EESTI NSV TEADUSTE AKADEEMIA TOIMETISED. V KÖIDE BIOLOOGILINE SEERIA, 1956, NR, 1.

ИЗВЕСТИЯ АКАДЕМИИ НАУК ЭСТОНСКОЙ ССР. ТОМ V СЕРИЯ БИОЛОГИЧЕСКАЯ. 1956, № 1

\title{
О ВЛИЯНИИ ОСНОВНЫХ ПРОТИВОТУБЕРКУЛЕЗНЫХ ПРЕПАРАТОВ НА ЧУВСТВИТЕЛЬНОСТЬ БЕЛЫХ МЫШЕЙ К РАЗЛИЧНЫМ ТИПАМ КИСЛОРОДНОГО ГОЛОДАНИЯ
}

\author{
Г. А. МИХАИЛЕЦ, \\ кандидат медицинских наук
}

В одной из предыдущих работ (Михайлец, 1953) нами было показано, что стрептомицин при совместном профилактическом и лечебном его применении угнетает развитие токсического отека легких у животных, вызванного окислами азота. Однако даже в тех случаях, когда у подопытных животных развивался выраженный отек легких, они, как правило, погибали в более поздние сроки, чем контрольные животные. Это навело нас на мысль, что стрептомицин, помимо противоотечного действия, наблюдаемого при токсическом отеке легких, оказывает еще, повидимому, и определенное влияние на чувствительность животных к кислородному голоданию.

Поскольку в патогенезе туберкулеза кислородная недостаточность с нарушением окислительных процессов имеет весьма существенное значение, мы специально занялись изучением влияния основных противотуберкулезных препаратов на чувствительность белых мышей к различным видам кислородного голодания.

\section{I. Влияние стрептомицина, фтивазида и ПАСК на чувствительность белых мышей к кислородному голоданию от пониженного парциального давления кислорода во вдыхаемом воздухе}

В первой серии опытов кислородное голодание у белых мышей вызывалось по методу В. А. Константинова (1949). Две мыши, одинакового пола и веса (одна контрольная и другая подопытная), сажались в герметический сосуд объемом 540 мл, и отмечалась продолжительность их жизни ${ }^{1}$. Подопытным животным за 1 час до помещения их в герметический сосуд вводнлся подкожно раствор стрептомицина из расчета 250 единиц антибиотика на 1 г веса тела. Контрольные мыши получали соответствующее по объему количество физиологического раствора, вводимого тем же путем. Результаты этих опытов представлены на рис. 1.

Из рисунка видно, что в подавляющем большинстве опытов (в 16 из 20) продолжительность жизни белых мышей, получавших антибиотик,

1 При такой методике постановки опытов смерть животных, как показал В. А. Қонстантинов (1950), зависит в основном от уменьшения парциального давления кислорода во вдыхаемом воздухе, а не от увеличения содержания углекислоты. 
была значительно больше, чем контрольных. Средняя продолжительность жизни подопытных животных составляла 50,7 минуты, контрольных 36 минут. (Разница между средней продолжительностью жизни подопытных и контрольных мышей статистически достоверна).

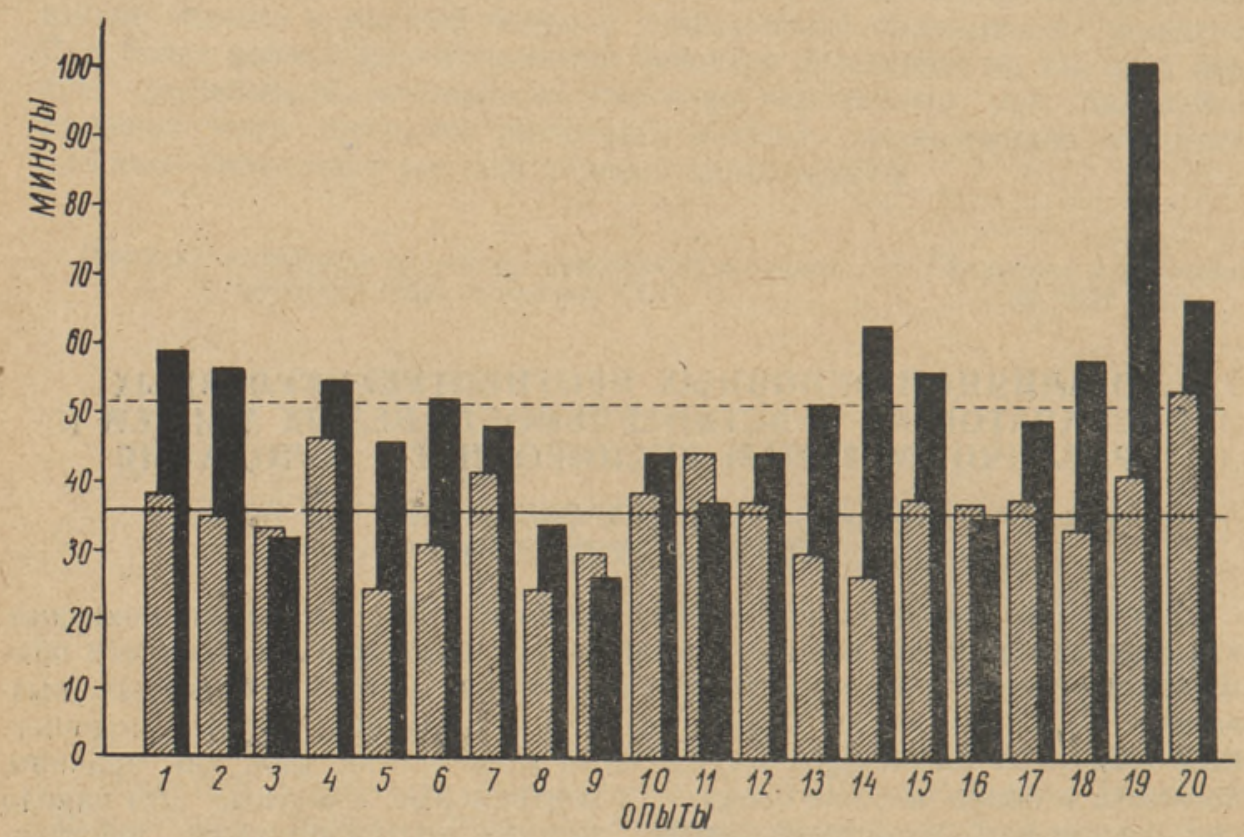

Рис. 1. Влияние стрептомицина на продолжителььость жизни белых мышей в герметическом сосуде. Сплошные черные столбики - продолжительность жизни подопытных животных, заштрихованные столбики - продолжительность жизни контрольных животных

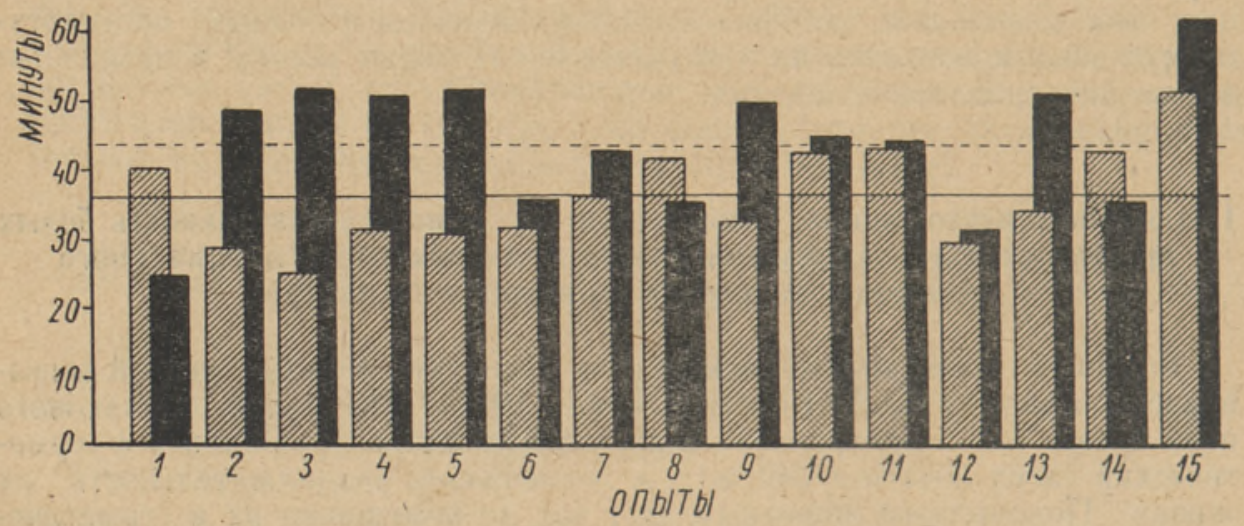

Рис. 2. Влияние ПАСК на продолжительность жизни белых мышей в герметическом сосуде. Обозначения те же, что и на рис. 1.

ПАСК в аналогичных опытах (препарат вводился животным внутрь за 1 час до помещения их в герметический сосуд из расчета 4 мг на 1 г веса тела) также оказала благоприятное действие на кислородное голодание (рис. 2). Средняя продолжительность жизни белых мышей, получавших ПАСК, равнялась 43,5 минуты, контрольных - 35,7 минуты. Меньшие дозы ПАСК, близкие к терапевтическим, применяемым для 
лечения туберкулеза у белых мышей, не оказали никакого влияния на чувствительность животных к кислородному голоданию (таблица 1).

Таблица 1

Влияние ПАСК в дозах 1 мг на 1 г веса тела на продолжительность жизни белых мышей в герметическом сосуде

\begin{tabular}{|c|c|c|c|c|c|}
\hline \multirow{2}{*}{$\begin{array}{c}\text { №№ } \\
\text { опытов }\end{array}$} & \multicolumn{2}{|c|}{$\begin{array}{c}\text { Продолжительность жизни } \\
\text { животных в минутах }\end{array}$} & \multirow{2}{*}{$\begin{array}{c}\text { №№ } \\
\text { опытов }\end{array}$} & \multicolumn{2}{|c|}{$\begin{array}{l}\text { Продолжительность жизни } \\
\text { животных в минутах }\end{array}$} \\
\hline & подопытных & контрольных & & подопытных - & контрольных \\
\hline \multirow[t]{2}{*}{$\begin{array}{l}1 \\
2 \\
3 \\
4 \\
5\end{array}$} & $\begin{array}{l}35 \\
48 \\
38 \\
43 \\
36\end{array}$ & $\begin{array}{l}43 \\
55 \\
32 \\
47 \\
38\end{array}$ & $\begin{array}{r}6 \\
7 \\
8 \\
9 \\
10\end{array}$ & $\begin{array}{l}41 \\
31 \\
22 \\
75 \\
23\end{array}$ & $\begin{array}{l}39 \\
24 \\
25 \\
58 \\
29\end{array}$ \\
\hline & \multicolumn{2}{|c|}{ средняя } & & 39,2 & 39,0 \\
\hline
\end{tabular}

Иная картина наблюдалась в опытах с фтивазидом. Дозы этого препарата 1 мг на 1 г веса тела мыши, как правило, ускоряли гибель подопытных животных. Так, средняя продолжительность жизни белых мышей, получавших фтивазид, равнялась 32,5 минуты, а контрольных 38,4 минуты (средние данные из 20 опытов).

.. В следующих опытах кислородное голодание вызывалось разрежением атмосферного воздуха.

8 мышей (4 контрольные и 4 подопытные) помещались в эксикатор, из которого постепенно в течение 25 минут выкачивался воздух до разрежения $140 \mathrm{~mm} \mathrm{Hg}$. Для исключения влияния выделявшейся животными углекислоты она связывалась при помощи химического поглотителя. Продолжительность опыта равнялась 2 часам. Результаты опытов представлены в таблице 2.

Таблица 2

Влияние основных противотуберкулезных препаратов на чувствительность белых мышей к понижению парциального давления кислорода во вдыхаемом воздухе

\begin{tabular}{|c|c|c|c|c|c|}
\hline $\begin{array}{c}\text { №을 } \\
\text { серий } \\
\text { опытов }\end{array}$ & Препараты & $\begin{array}{l}\text { Коли- } \\
\text { чество } \\
\text { мышей }\end{array}$ & $\begin{array}{l}\text { Дозы } \\
\text { препа- } \\
\text { ратов }\end{array}$ & $\begin{array}{c}\text { Средняя продол- } \\
\text { жительность } \\
\text { жизни мышей } \\
\text { в минутах }\end{array}$ & $\begin{array}{l}\text { Количество } \\
\text { выживших } \\
\text { животных }\end{array}$ \\
\hline $\begin{array}{l}1 \\
2 \\
3 \\
4\end{array}$ & $\begin{array}{l}\text { Стрептомицин } \\
\text { Контроль } \\
\text { Стрептомицин } \\
\text { Контроль } \\
\text { ПАСК } \\
\text { Контроль } \\
\text { Фтивазид } \\
\text { Контроль } \\
\text { Фтивазид } \\
\text { Контроль }\end{array}$ & $\begin{array}{l}16 \\
16 \\
16 \\
16 \\
12 \\
12 \\
16 \\
16 \\
16 \\
16\end{array}$ & $\begin{array}{c}5000 \text { ед. } \\
3000 \text { ед. } \\
1 \overline{\mathrm{Mr} / \mathrm{r}} \\
1 \overline{\mathrm{Mr} / \mathrm{r}} \\
0,5 \overline{\mathrm{Mr} / \mathrm{r}}\end{array}$ & $\begin{array}{l}73 \\
31 \\
49 \\
26 \\
24,7 \\
24,2 \\
27,3 \\
32,5 \\
33 \\
32\end{array}$ & $\begin{array}{c}9 \\
0 \\
10 \\
3 \\
0 \\
0 \\
0 \\
1 \\
0 \\
0\end{array}$ \\
\hline
\end{tabular}

Как видно из таблицы, в этих опытах стрептомицин оказал выраженное действие на чувствительность белых мышей к кислородному голоданию. В первой серии опытов из 16 животных, получавших антибиотик в дозах 5000 единиц на мышь, 9 пережили 2-часовое пребывание в атмосфере, степень разрежения которой равнялась 140 мм $\mathrm{Hg}$, в то время как все контрольные животные погибли. Значительно большей была и сред- 
няя продолжительность жизни мышей, получавших стрептомицин и погибших во время опыта, по сравнению с контрольными животными.

По данным Р. О. Драбкиной и Е. П. Синельниковой (1951), терапевтические дозы стрептомицина при лечении туберкулеза белых мышей составляют 3000 единиц на животное в сутки. Естественно поэтыму было выяснить влияние терапевтических доз антибиотика на чувствительность белых мышей к кислородному голоданию. Результаты этих опытов (таблица 2 , серия 2) убедительно показывают, что стрептомицин и в терапевтических дозах, применяемых для лечения туберкулеза у белых мышей, оказывает значительное влияние на кислородное голодание: при введении антибиотика значительно увеличивается как продолжительность жизни животных, так и их выживаемость.

ПАСК в дозах 1 мг на 1 г веса тела мыши не оказала в этих опытах никакого влияния на чувствительность животных к кислородному голоданию.

Некоторое уменьшение продолжительности жизни белых мышей, помещенных в атмосферу пониженного парциального давления кислорода, наблюдалось под влиянием фтивазида в дозах 1 мг на 1 г веса тела. Применение меньших доз этого препарата (серия 5) не вызвало никаких изменений со стороны чувствительности белых мышей к кислородному голоданию.

\section{2. Влияние основных противотуберкулезных препаратов на чувствитель- ность белых мышей к кислородному голоданию, вызванному введением азотистокислого натрия}

При введении в организм животных азотистокислого натрия образуется метгемоглобин и резко снижается артериальное давление. Таким образом, при отравлении этим веществом наблюдается кровяной и сердечно-сосудистый тип кислородного голодания (Петров, 1954). Однако эти патологические процессы имеют место не у всех видов животных. Как хорошо известно (Правдин, 1947), у белых мышей, кур и лягушек метгемоглобин вовсе не образуется. Поэтому при введении белым мышам нитрита натрия кислородное голодание наступает в основном от резкого понижения кровяного давления и относится, следовательно, к сердечнососудистому типу кислородной недостаточности.

Прежде, чем перейти к изучению влияния противотуберкулезных грепаратов на чувствительность белых мышей к отравлению их азотистокислым натрием, мы определили токсичность нитрита натрия для этого вида животных в диапазоне доз от 0,1 до 0,25 мг на 1 г веса тела. Действие каждой дозы испытывалось на 10 животных. Было установлено, что высшая переносимая доза азотистокислого натрия для белых мышей равна 0,125 мг на 1 г веса тела; от 0,25 мг на 1 г веса тела погибали все животные. Обработка данных по методу «накопления частот» (метод Беренса) показала, что $\mathrm{LD}_{50}=0,185 \mathrm{mr} / \mathrm{r}$.

Изучавшиеся вещества - стрептомицин, ПАСК и фтивазид - вводились белым мышам за 1 час до подкожной инъекции им раствора нитрита натрия. Результаты опытов представлены в таблице 3.

Из таблицы видно, что стрептомицин оказывает существенное влияние на чувствительность белых мышей к отравлению их нитритом натрия: мыши, получавшие антибиотик, жили значительно дольше, чем контрольные животные. Однако, хотя етрептомицин заметно увеличивает продолжительность жизни мышей, отравленных азотистокислым натрием, он не влияет на их выживаемость.

По данным Г. А. Степанского (1950), терапевтический эффект снотворных средств (уретана и веронала) при отравлении белых крыс и 
Влияние основных противотуберкулезных препаратов на чувствительность белых мышей к отравлению азотистокислым натрием

\begin{tabular}{|c|c|c|c|c|c|c|}
\hline $\begin{array}{c}\text { №№ } \\
\text { серий } \\
\text { опытов }\end{array}$ & Препараты & $\begin{array}{l}\text { Коли- } \\
\text { чество } \\
\text { мышей }\end{array}$ & $\begin{array}{l}\text { Дозы } \\
\text { нитрита } \\
\text { натрия } \\
\text { в мr/r }\end{array}$ & $\begin{array}{c}\text { Дозы } \\
\text { препа- } \\
\text { ратов }\end{array}$ & $\begin{array}{c}\text { Средняя продол- } \\
\text { жительность } \\
\text { жизни мышей } \\
\text { в минутах }\end{array}$ & $\begin{array}{c}\text { Количество } \\
\text { выживших } \\
\text { животных }\end{array}$ \\
\hline 1 & 2 & 3 & 4 & 5 & 6 & 7 \\
\hline $\begin{array}{l}1 \\
2 \\
3\end{array}$ & $\begin{array}{l}\text { Стрептомицин } \\
\text { Контроль } \\
\text { Стрептомицин } \\
\text { Контроль } \\
\text { Стрептомицин } \\
\text { Контроль } \\
\text { ПАСК } \\
\text { Контроль } \\
\text { Фтивазид } \\
\text { Контроль }\end{array}$ & $\begin{array}{l}27 \\
27 \\
30 \\
30 \\
22 \\
22 \\
11 \\
11 \\
12 \\
12\end{array}$ & $\begin{array}{l}0,2 \\
0,2 \\
0,25 \\
0,25 \\
0,25 \\
0,25 \\
0,25 \\
0,25 \\
0,25 \\
0,25\end{array}$ & $\mid \begin{array}{c}5000 \text { ед. } \\
2500 \text { ед. } \\
5000 \text { ед. } \\
1 \overline{\mathrm{mr}} / \mathrm{r} \\
1 \overline{\mathrm{Mr} / \mathrm{r}}\end{array}$ & $\begin{array}{l}74,9 \\
48,4 \\
35,4 \\
27,2 \\
39,1 \\
24,5 \\
23,8 \\
23,6 \\
26 \\
26,8\end{array}$ & $\begin{array}{l}8 \\
6 \\
0 \\
0 \\
0 \\
0 \\
0 \\
0 \\
0 \\
0\end{array}$ \\
\hline
\end{tabular}

кошек нитритом натрия зависит от степени отравления и от дозы наркотика: автор наблюдал благотворное влияние только в тех случаях, когда животные подвергались воздействию абсолютно смертельных доз азотистокислого натрия, а снотворные вводились в дозах, вызывающих сон, близкий к фйзиологическому. При отравлении же белых крыс или кошек меньшими дозами, вызывающими смерть у $2 / 3$ животных, введение снотворных, наоборот, оказывало некоторое отрицательное действие. Дозы снотворных, вызывающие наркоз, также ускоряли гибель подопытных животных.

Таблица 4

Влияние основных противотуберкулезных препаратов на чувствительность белых мышей к отравлению их цианистым калием

\begin{tabular}{|c|c|c|c|c|c|c|c|}
\hline & & & Поги & 10 ЖИ & отных & через & \\
\hline $\begin{array}{l}\text { серий } \\
\text { опытон }\end{array}$ & Препараты и их дозы & $\begin{array}{c}\text { Количество } \\
\text { животных }\end{array}$ & $\begin{array}{c}1 \\
\text { час }\end{array}$ & $\begin{array}{c}3 \\
\text { часа }\end{array}$ & $\begin{array}{c}6 \\
\text { часов }\end{array}$ & $\begin{array}{c}24 \\
\text { часа }\end{array}$ & $\begin{array}{c}\text { Выжило } \\
\text { животных }\end{array}$ \\
\hline 1 & 2 & 3 & 4 & 5 & 6 & 7 & 8 \\
\hline 3 & $\begin{array}{l}\text { Стрептомицин } 5000 \text { ед. } \\
\text { Контроль } \\
\text { Стрептомицин } 2500 \text { ед. } \\
\text { Контроль } \\
\text { Фтивазид } 0,5 \mathrm{mr} / \mathrm{r}^{-} \\
\text {Контроль } \\
\text { ПАСК } 1 \text { мг/г } \\
\text { Контроль }\end{array}$ & $\begin{array}{l}63 \\
63 \\
40 \\
40 \\
20 \\
20 \\
20 \\
20\end{array}$ & $\begin{array}{r}17 \\
42 \\
26 \\
26 \\
11 \\
12 \\
10 \\
9\end{array}$ & $\begin{array}{l}33 \\
51 \\
28 \\
28 \\
15 \\
17 \\
15 \\
15\end{array}$ & $\begin{array}{l}36 \\
55 \\
31 \\
29 \\
17 \\
18 \\
15 \\
18\end{array}$ & $\begin{array}{l}36 \\
55 \\
32 \\
31 \\
17 \\
18 \\
16 \\
18\end{array}$ & $\begin{array}{r}27 \\
8 \\
8 \\
9 \\
3 \\
2 \\
4 \\
2\end{array}$ \\
\hline
\end{tabular}

В случаях же применения стрептомицина при отравлении белых мышей нитритом натрия, как видно из таблицы 3 , не отмечается подобной зависимости. Антибиотик оказывает благотворное влияние как при отравлении животных абсолютно смертельными дозами азотистокислого натрия, так и в тех случаях, когда употребляются меньшие дозы яда.

ПАСК и фтивазид не вызывали никаких изменений в чувствительности животных к воздействию нитрита натрия. 


\section{3. Влияние стрептомицина, фтивазида и ПАСК на чувствительность белых мышей к кислородному голоданию тканевого типа}

Кислородное голодание тканевого типа вызывалось в наших опытах у белых мышей подкожным введением им раствора цианистого калия из расчета 10 мг сухого вещества на 1 кг веса тела. Поскольку препарат весьма нестоек, растворы его приготавливались ex tempore. Стрептомицин, фтивазид и ПАСК вводились, как и в предыдущих опытах, за 1 час до инъекции раствора цианистого калия.

Результаты опытов представлены в таблице 4.

Как видно из таблицы, стрептомицин в дозах 5000 единиц на мышь значительно увеличивает выживаемость животных, отравленных цианистым калием. Меньшие дозы антибиотика, а также фтивазид в дозах 0,5 мг на 1 г веса тела и ПАСК в дозах 1 мг на 1 г веса тела не оказывает никакого влияния на чувствительность животных к этому яду.

\section{Выводы}

1. Проведенные исследования убедительно показали, что стрептомицин в дозах 2500-5000 единиц на мышь заметно понижает чувствительность белых мышей к кислородному голоданию, вызванному как понижением парциального давления кислорода во вдыхаемом воздухе, так и отравлением животных азотистокислым натрием или цианистым калием.

2. Фтивазид и ПАСК в терапевтических дозах, применяемых для лечения туберкулеза у белых мышей, не оказывают существенного действия на течение этих патологических процессов.

3. Возможно, что при лечении туберкулезных больных стрептомицином определенное значение имеет влияние этого вещества на течение кислородной недостаточности.

Институт әкспериментальной и клинической медицины Академии наук Эстонской ССР
Поступила в редакцию $13 \times 1955$

\section{ЛИТЕРАТУРА}

Д ра бкин а Р. О. и Синельников а Е. П., 1951. О распределении стрептомицина в жидкостях, органах и тканях организма и его выделении. Проблемы туберкулеза, 5 .

Кон с т а т. н о в В. А., 1949. Об удлинении продолжительности жизни белых мышей в герметически закрытом сосуде. Сообщение I. Влияние наркоза. В книге Механизмы патологических реакций, вып. $11-15$, Ленинград.

Константинов В. А., 1950 . Об удлинении продолжительности жизни белых мышей в герметически закрытом сосуде. Сообщение 3. Содержание кислорода и углекислоты воздуха в момент гибели мышей, бывших в закрытом сосуде при разных условиях, В книге Механизмы патологических реакщий, вып. 16-20, Ленинград.

М и х а йлец Г. А., 1953. Влияние стрептомицина на течение и исход токсического отека легких. Фармакология и токсикология, 4.

Петр в И. Р., 1954. Воспронзведение у жнвотных кислородного голодания. В книге Воспроизведение заболеваний у животных для экспериментально-терапевтических исследований, Медгиз.

П р а вд и н Н. С., 1947. Методика малой токсикологии промышленных ядов. Медгиз.

С теп ан ски й Г. А., 1950. Исследование выносливости животных, подвергшихся воздействию снотворных средств, по отношению к различным степеням отравлением нитрита натрия, - Фармакология и тсксикология, 3. 


\title{
PEAMISTE TUBERKULOOSIVASTASTE PREPARAATIDE MOJUST \\ VALGETE HIIRTE TUNDLIKKUSELE MITUT TUUPI \\ HAPNIKUVAEGUSE SUHTES
}

\author{
G. MIHHAILETS,
}

meditsiiniteaduste kandidaat

\section{LOHIKOKKUVOTE}

Uuriti streptomütsiini, ftivasiidi ja PASK-i mõju valgete hiirte tundlikkusele hapnikuvaeguse suhtes, mida tekitati niihästi hapniku partsiaalrõhu vähendamisega sissehingatavas õhus kui ka loomade mürgistamisega naatriumnitriidi ja kaaliumtsüaniidi abil. Tehti kindlaks, et streptomütsiin annustes 2500-5000 ühikut hiire kohta avaldab tunduvat toimet valgete hiirte tundlikkusele mitut tüüpi hapnikuvaeguse suhtes, pikendades katsealuste loomade elu kestust. Ftivasiid ja PASK ei avalda niisugust toimet terapeutilistes annustes, missuguseid rakendatakse valgete hiirte eksperimentaalse tuberkuloosi ravimiseks.

\section{ÜBER DIE WIRKUNG DER WICHTIGSTEN TUBERKULOSE- HEILMITTEL AUF DIE EMPFINDLICHKEIT DER WEISSEN MAUS GEGENUBER VERSCHIEDENEN ARTEN DES SAUERSTOFFMANGELS}

\author{
G. MIHHAILETZ
}

\section{ZUSAMMENFASSUNG}

Es wurde die Wirkung von Streptomycin, Phthivazid und PASNa auf die Empfindlichkeit der weissen Maus dem Sauerstoffmangel gegenüber untersucht. Der letztere wurde sowohl durch Senkung des Sauerstoffpartialdruckes in der einzuatmenden Luft wie auch durch Vergiftung der Versuchstiere mit Natriumnitrit oder Zyankali hervorgerufen. Es wurde festgestellt, dass Streptomycin in der Dosis 2500-5000 IE pro Maus eine deutliche Wirkung auf die Empfindlichkeit dem Sauerstoffmangel verschiedener Art gegenüber ausübt, indem es die Lebensdauer der Versuchstiere verlängert. Phthivazid und PASNa zeigen dagegen in therapeutischen Dosen, die bei der Behandlung der experimentellen Tuberkulose der weissen Maus angewandt werden, keine solche Wirkung. 